\title{
A Longitudinal Study Comparing Scaling, Osseous Surgery and Modified Widman Procedures
}

\author{
Results after One Year
}

\author{
William Becker, ${ }^{\star}$ Burton E. Becker, Clifford Ochsenbein, \\ Gloria Kerry, † Raul Caffesse, $\ddagger$ Edith C. Morrison§ and \\ John Prichard
}

Accepted for publication 2 October 1987

\begin{abstract}
THE PURPOSE OF THIS STUDY was to compare, longitudinally, the effectiveness of scaling and root planing, osseous surgery, and the modified Widman procedures. The study was carried out in a private practice setting. Sixteen adult patients with moderate to advanced adult periodontitis were treated with initial scaling and oral hygiene procedures. Posthygiene data were used for comparison of changes in probing depth, clinical attachment levels and gingival recession. The initial examination data were used to compare changes in plaque and gingival indices. Frequency distributions were used to compare changes that occurred at individual sites. At one year, plaque and gingival indices were significantly reduced when compared with the initial examination. At one year, shallow pockets $(1-3 \mathrm{~mm})$ were reduced when compared to posthygiene. Four- to six-millimeter pockets were significantly reduced by the three procedures. Osseous surgery and modified Widman had significantly greater pocket reduction when compared with scaling. For pockets $>7 \mathrm{~mm}$, osseous surgery and the modified Widman had significantly greater reduction when compared with scaling. For pockets $1-3 \mathrm{~mm}$ at one year osseous surgery had significantly greater clinical attachment loss when compared with scaling. For 4-6 mm pockets at one year, the three procedures had slight gains in clinical attachment levels. The results were similar for pockets with $>7 \mathrm{~mm}$.

Interproximal soft tissue craters were measured for six postoperative weeks. Initially, the modified Widman had a higher percentage of soft tissue craters when compared with osseous surgery. At six weeks, however, there were no significant differences when the surgical procedures were compared. Recession was measured at each examination. Recession for 1$3 \mathrm{~mm}$ pockets at one year was greater for osseous surgery when compared with scaling and the modified Widman. Recession for 4-6 $\mathrm{mm}$ and $>7$ pockets was greater for the surgical procedures than scaling. The results from this study indicate that with three-month maintenance recalls, both the modified Widman and osseous surgery are effective for pocket reduction, and each will produce a slight gain of clinical attachment over one year. Scaling was effective at maintaining attachment levels but was not as effective in reducing pocket depth.
\end{abstract}

Treatment of moderate to advanced periodontal disease has traditionally consisted of both nonsurgical and surgical therapy. Over the past 20 years there have been

\footnotetext{
* Assistant clinical professor, graduate periodontics, University of Southern California, Los Angeles, CA. Associate clinical professor, graduate periodontics, University of Michigan, Ann Arbor, MI.

$\dagger$ Professor, Department of Periodontics, University of Michigan.

$\ddagger$ Professor, Chairman, Department of Periodontics, University of Michigan.

$\S$ Assistant professor of periodontics and associate research scientist, University of Michigan.
}

several longitudinal studies that compared the effectiveness of various procedures in arresting the progression of periodontitis. ${ }^{1-10}$ Similarly, there have been several retrospective studies that have documented the effectiveness of periodontal therapy. ${ }^{11-13}$ Limited information is available regarding the long-term benefits of osseous surgery. The results from many of these studies have been questioned by clinicians because the surgical techniques for osseous recontouring have not been clearly defined. ${ }^{1-7}$ Studies that have been reported compared osseous surgery with various surgical and non- 
surgical procedures. ${ }^{1-10}$ Rosling et al. ${ }^{5}$ compared healing after various surgical procedures had been performed. The patients received professional cleaning and oral hygiene instructions every two weeks for two years. The greatest loss of clinical attachment occurred for those sites that received osseous surgery. Hill et al., ${ }^{7}$ in a two-year longitudinal study, reported the greatest amount of attachment loss after pocket elimination and the least attachment loss after scaling and root planing. Smith et al. $^{8}$ compared osseous surgery with flap curettage. The surgical techniques for both procedures were clearly defined. At six months pockets treated with osseous surgery had greater attachment loss when compared with flap curettage. Pocket reduction achieved with osseous surgery was maintained over six months, while pockets treated with flap curettage tended to recur. This present research is unusual because it was performed in a private practice setting but was planned and carried out with the cooperation of the University of Michigan School of Dentistry, Department of Periodontics.

This study compared the longitudinal effectiveness of scaling and root planing, the modified Widman flap procedure and osseous surgery. Each technique was carried out by a periodontist who is a proponent of that technique and is experienced in the application of the technique. This is an ongoing study, and results after one year will be reported in this paper. The parameters studied were changes in gingival inflammation, plaque scores, probing depths and clinical attachment levels. In addition, postsurgery, interproximal soft tissue cratering and gingival recession were analyzed. Patient means and frequency distribution analysis were used to compare changes between procedures.

\section{METHODS}

Prior to initiating the study, one clinician (WB) was trained and calibrated in measuring and recording clinical attachment levels. Training took place at the University of Michigan, graduate periodontics department. All measurements in this study were performed by the same examiner (WB). All subsequent measurements were made without access to previous measurement recordings.

Clinicians knowledgeable in both modified Widman surgery (GK) and osseous surgery (CO), (BEB) and (WB) participated in this study. The modified Widman procedure was performed according to Ramfjord and Nissle. ${ }^{14}$ The guidelines for osseous surgery were described by Ochsenbein. ${ }^{15}$

The study population consisted of 16 patients ranging in age from 30 to 57 years. The mean age was 42 years. There were 11 females and five males. Each patient initially had two or more sites equal to or greater than $6 \mathrm{~mm}$ of clinical attachment loss in the posterior sextants of the dentitions. Anterior teeth were not included in the study. All patients were diagnosed as having moderate to advanced adult periodontitis. The purpose of the study was explained to the patients and each signed a surgical consent form and agreed to comply with maintenance and reexamination schedules for a minimum of five years.

The experimental design is present in Figure 1. All patients had an initial baseline examination at which time probing depth and clinical attachment levels from the cementoenamel junction or other fixed tooth landmarks were recorded. Six probing measurements were determined for each tooth. The four proximal measurements were made with the probe being held parallel to the long axis of the tooth and as close to the contact area as possible. One measurement was taken on the

Initial examination

$$
\begin{gathered}
\text { Study Design } \\
(n=16)
\end{gathered}
$$

PD-FGM-BP

AL-CEJ-BP

GI-Löe and Silness

PI-Silness and Löe

Mobility-Miller's classification

Furcations-Glickman's classification

X-rays

Photos

Oral hygiene instructions, and initial scaling and root planing two 1-hr sessions (hygienist)

Postscaling data collection 3-4 weeks' postscaling

Random selection of either

I. Scaling and root planing with anesthesia (periodontist)

II. Osseous surgery

III. Modified Widman

4-6 weeks' postscaling

Random choice of maxilla or mandible

Random choice of left or right

Posterior sextants only

Crater index postsuturing

Antibiotic coverage for 4 days

All procedures photographed

Suture removal and $\mathrm{OHI}$

10 days' postoperatively

Crater index

Teeth polished

Photos

Weekly polishing of teeth

6 weeks

Carter index

Photos

Postsurgery examination 8 Weeks postoperatively

$\mathrm{PD}$

$\mathrm{AL}$

GI

PI

Mobility

Furcations

Photos

Figure 1. Chart of Experimental Protocol. 
midbuccal tooth aspect and one measurement was taken at the midlingual tooth aspect. All measurements were recorded with the Michigan $\mathrm{O}$ periodontal probes with Williams markings. Gingival inflammation was recorded for each tooth in the posterior sextants using the method described by Löe and Silness. ${ }^{16}$ Bacterial plaque was scored according to the method described by Silness and Löe. ${ }^{17}$ Tooth mobility was recorded using the Miller index,${ }^{18}$ and furcations were assessed using the Glickman index. ${ }^{19}$ Each patient had a complete dental radiographic survey using a nonstandardized, parallel film placement technique.

The patients had two one-hour sessions of oral hygiene instruction together with root planing and scaling. These were performed by dental hygienists without local anesthesia. The objective of the initial scaling was to remove both supra- and subgingival calculus and to evaluate patient compliance with oral hygiene procedures. Teeth that initially showed signs of mobility greater than one were given selective occlusal adjustments.

\section{DATA ARRANGEMENT}

The initial examination data were used for comparison of the gingival and plaque scores and the frequency distributions of sites according to probing depth and clinical attachment. These data can be used to compare changes that occurred as a result of the initial preparation phase of therapy. The posthygiene data were recorded three to four weeks after the initial scaling was completed. These data were considered baseline for changes in probing depth, clinical attachment levels and recession, and were used for comparative changes for the three methods of treatment.

The data are based on patient means and were stratified according to probing depth and clinical attachment levels recorded at the posthygiene examination. The probing depth sites were classified as follows; 1 to $3 \mathrm{~mm}, 4$ to $6 \mathrm{~mm}$ and equal to or greater than $7 \mathrm{~mm}$. The clinical attachment level measurements were classified from 0 to $2 \mathrm{~mm}, 3$ to $5 \mathrm{~mm}$ and $>6 \mathrm{~mm}$. The patients were reexamined eight weeks, six months and one year postsurgery.

\section{STATISTICAL ANALYSIS}

To test the effect of equal treatment in the three levels of severity, the one-way analysis of variance (ANOVA) was used. The test was performed on patient means for changes in gingival and plaque scores, probing depth, clinical attachment levels and gingival recession. If the hypothesis of equal treatment was rejected at the 0.05 level of significance using ANOVA, Scheffe's method for multiple comparisons was used to determine which of the treatments differed. The effectiveness of each treatment from posthygiene was evaluated by the pairwise $t$ test at each interval. Changes in gingival and plaque scores were also analyzed by the Kruskal-Wallis nonparametric test and the Wilcoxon matched-pair statistical test. The Fisher's exact test was used to determine the significance of changes in the interproximal crater measurements. Percentage and frequency distributions were used to determine changes in individual sites for both probing depth and clinical attachment levels.

\section{SURGICAL PROCEDURES}

Modified Widman Procedure. The surgical and nonsurgical procedures were performed the same day. Prior to surgery the patients were premedicated intravenously, after which appropriate local anesthesia was administered. The modified Widman procedure was performed according to that reported by Ramfjord and Nissle. ${ }^{14}$ On the buccal, palatal, labial and lingual aspects the initial internal-beveled incisions were located 0.5 to $1 \mathrm{~mm}$ apical to the gingival margin. These incisions were blended into, and preserved as much of, the interdental papillae as was possible. A secondary intrasulcular incision was used to detach the marginal gingival tissue collar. Full thickness mucoperiosteal flaps were then elevated to expose 2 to $4 \mathrm{~mm}$ of alveolar bone. When necessary, vertical relaxing incisions were used to provide adequate access for soft tissue and root debridement. The granulation tissue was removed, and the roots were planed smooth with a combination of ultrasonic and hand instruments. The flaps were compressed with warm saline sponges to achieve maximum flap adaptation. In two instances, osteoplasty was performed in order to achieve better flap adaptation. The flaps were sutured coronally with 4-0 interrupted sutures, attempting to place the flap margins at their original level.

Osseous Surgery. Inverse bevel incisions were placed 1 to $2 \mathrm{~mm}$ apical to the free gingival margins, and full thickness mucoperiosteal flaps were elevated past the mucogingival junction. In order to avoid including too many healthy sites in the surgical field, vertical incisions were placed one tooth anterior to the tooth with the deepest probing depths. The flaps were not extended anterior to the mesial aspect of the canine. The gingival soft tissue collar and granulation tissue were removed with curettes. The root surfaces were debrided with a combination of ultrasonic and hand instruments. The roots were planed until they felt smooth.

In the maxillary arch, osseous defects were primarily reduced from the palatal aspect. The craters were reduced by creating a gentle slope of ten to 15 degrees toward the palatal aspect. The palatal ramp was created with high speed instrumentation and water coolant. Palatal radicular bone was reduced with hand instruments. The palatal radicular bone was either even with the adjacent interdental bone or slightly apical to it. The buccal aspects were managed primarily by osteoplasty, attempting to produce a flat buccal profile. The 
amount of buccal bone reduced was dictated by the initial depth of the craters, the dimension of the root trunks, and the relationship of the interdental boneheight to the buccal radicular bone. ${ }^{15}$ In no instances were uninvolved furcations jeopardized. Buccal osteoectomy was performed with hand instrumentation. The buccal and lingual flaps were sutured with 4-0 continuous sling silk sutures. This allowed for placement of the flap margins at or slightly coronal to the alveolar crest. The vertical incisions were sutured with interrupted 4-0 silk sutures.

In the mandibular arch, osseous surgery was performed primarily from the lingual aspect. ${ }^{15,20}$ The mandibular molars have a 20 - to 30 -degree lingual inclination. ${ }^{20}$ The lingual tooth position usually places interdental craters lingual to the contact area. Crater reduction using this approach was primarily done by osteoplasty. Removal of radicular lingual bone was done with hand instruments. The lingual radicular bone was usually even or slightly apical to the adjacent interdental bone. Lingual radicular bone was never sacrificed at the expense of exposing furcations. On the buccal aspect, osseous surgery was done primarily by osteoplasty. Thick ledges and bony protuberances were removed with high speed instrumentation and water coolant. The buccal osseous profile was either flat or slightly apical to the interdental bone.

Osteoectomy was sometimes performed with hand instrumentation but in no instances were the furcations jeopardized. The flaps were sutured with 4-0 continuous sling sutures and were positioned at, or slightly coronal to, the alveolar crest. The vertical incisions were sutured with interrupted $4-0$ silk sutures. Osseous surgery was alternately performed by CO, BEB and WB. Deep intrabony defects were encountered in two sites. Osseous surgery in these areas would have required removal of too much supporting bone and, consequently, compromise was accepted.

\section{SCALING AND ROOT PLANING}

Sextants receiving scaling and root planing were anesthetized with local anesthesia and were performed by a periodontist (WB). The roots were debrided with a combination of ultrasonic and hand instrumentation. The roots were planed until they had hard, smooth surfaces. Deliberate soft tissue curettage was not performed. The root planing for each sextant took approximately one hour.

\section{INTERPROXIMAL SOFT TISSUE INDEX}

After suturing, the interdental areas were carefully examined for primary, interdental, soft-tissue closure. The closure was graded as being "open" or "closed." The interdental areas were examined weekly for six postoperative weeks.

All patients were placed on prophylactic antibiotics for a period of four days to prevent postoperative infection. Either tetracycline or erythromycin (1 gm per day) along with appropriate analgesics was prescribed. Dressings were not applied and the patients were requested to begin gentle brushing on the second postoperative day. The sutures were removed from seven to ten days postoperatively, and oral hygiene instructions were reinforced. The crowns were lightly scaled and polished weekly for six postoperative weeks. At the eighth postoperative week, the plaque and gingival indices, probing depths and clinical attachment levels were recorded. At 6 months and one year the reference measurement landmarks were occasionally polished out. When this ocurred, they were estimated. All measurements were taken at six months and one year. The evaluations will continue for five years.

\section{MAINTENANCE}

After the postsurgery examination, all patients were placed on a strict three-month maintenance recall. At these visits the oral hygiene was reviewed and the patients were given a one-hour session of scaling and root planing, after which the teeth were polished with a fluoride-containing paste.

\section{RESULTS}

Plaque Index. Figure 2 presents the data relating to mean changes in the plaque index. At one year, when compared with the first examination, there was a significant decrease in plaque scores for the three procedures. Results from the Kruskal-Wallis and Wilcoxon statistical tests were the same as those shown in Figure 2.

General Index. Figure 3 presents the mean gingival index values from the initial examination to one year. The data reflect the mean scores for each of the procedures and the changes in these scores between examinations. When compared with the initial examination each subsequent evaluation revealed a significant decrease in the gingival index for the three treatment methods. At one year the mean values had increased when compared with the postsurgery examination but were significantly less when compared with the initial examination. Results from the Kruskal-Wallis and Wilcoxon statistical tests were the same as those shown in Figure 3.

Probing Depths (1-3 mm posthygiene). Changes in probing for pocket depths in the 1- to 3-mm category are presented in Figure 4. At six months and one year, pockets that had scaling showed a slight increase in depth.

Postsurgery and at six months, sites receiving osseous surgery had a significant decrease in probing depth when compared to posthygiene. At one year, the mean probing depth was slightly less than at baseline. 


\section{Mean Changes in the Plaque Index}

Baseline to 1 Year

\begin{tabular}{|c|c|c|c|c|c|c|c|c|c|c|c|c|c|}
\hline & \multirow{2}{*}{$\begin{array}{c}\text { BASELINE } \\
\vdots \\
i\end{array}$} & \multicolumn{3}{|c|}{ Post-Hygienic Phase } & \multicolumn{3}{|c|}{ POST-SURGERY } & \multicolumn{3}{|c|}{6 HONTHS } & \multicolumn{3}{|c|}{ I YEAR } \\
\hline & & $\bar{x}$ & $\bar{\Delta}$ & $S, D$. & $\bar{x}$ & $\bar{\Delta}$ & S.D. & $\bar{x}$ & $\bar{\Delta}$ & S.D. & $\bar{x}$ & $\bar{\Delta}$ & S.R. \\
\hline SCALIHG & 1.47 & .31 & 1.16 & $.65^{\circ}$ & .24 & 1.23 & $.66^{*}$ & .35 & 1.12 & $.74 *$ & .42 & 1.05 & $.78^{*}$ \\
\hline OSSEOUS & 1.48 & .24 & 1.24 & $.69^{\circ}$ & .25 & 1.23 & $.66^{*}$ & .39 & 1.09 & $.85^{*}$ & .43 & 1.05 & $.94^{*}$ \\
\hline WI DMAN & 1.38 & .27 & 1.11 & $.71^{\circ}$ & .39 & .99 & $.73^{*}$ & .32 & 1.06 & $.86^{*}$ & .42 & .37 & $.93^{*}$ \\
\hline
\end{tabular}

$N=16$

- PalRwise t-test<.01

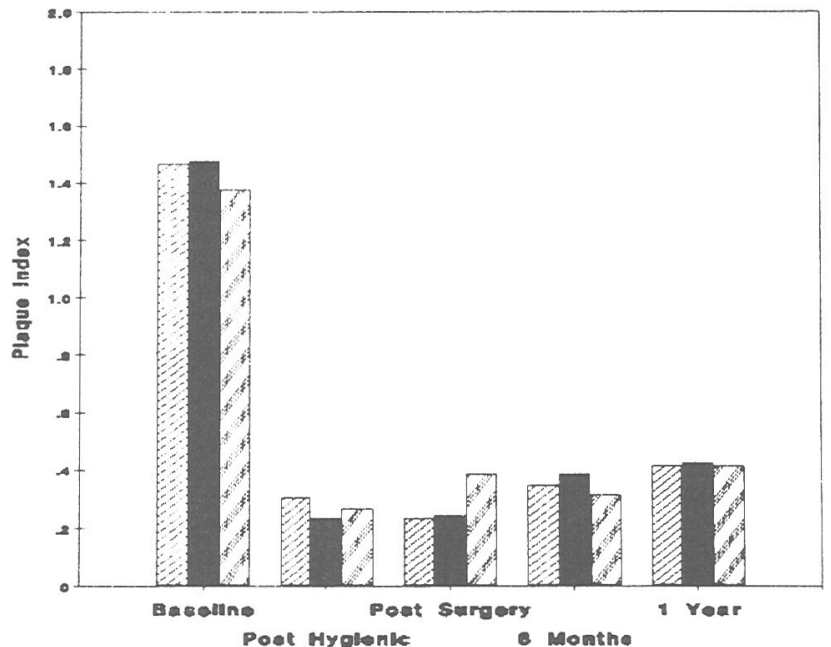

Figure 2. Mean changes in the plaque index from baseline to one year.

\section{Mean Changes in the Gingival Index} Baseline to 1 Year

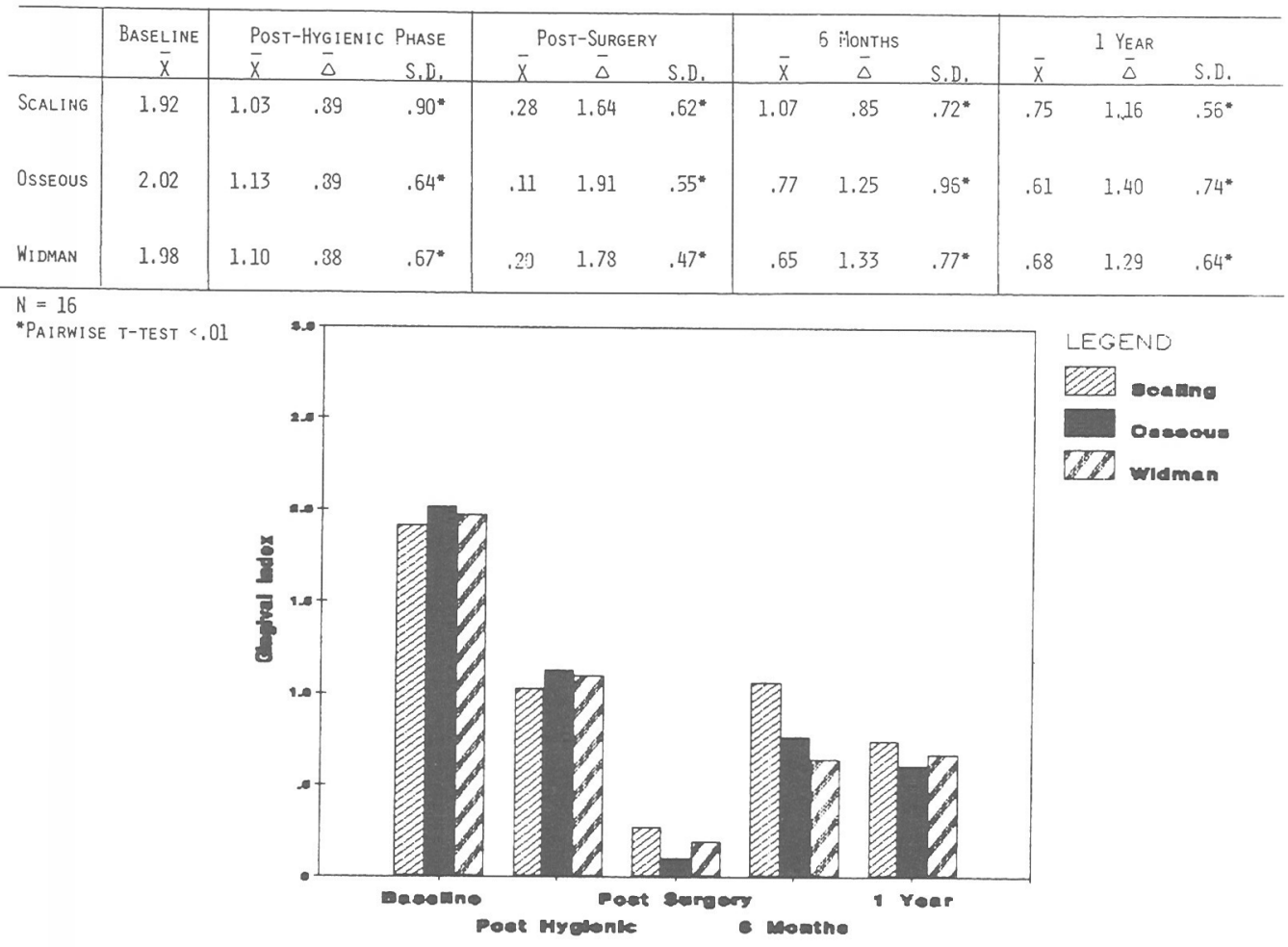

Figure 3. Mean changes in the gingival index from baseline to one year.
LEGEND

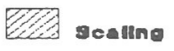

Osemou

एक Widmen 


\section{Changes in Probing Dopth \\ from Hygienic Phase \\ Pockets 1-3 mm}

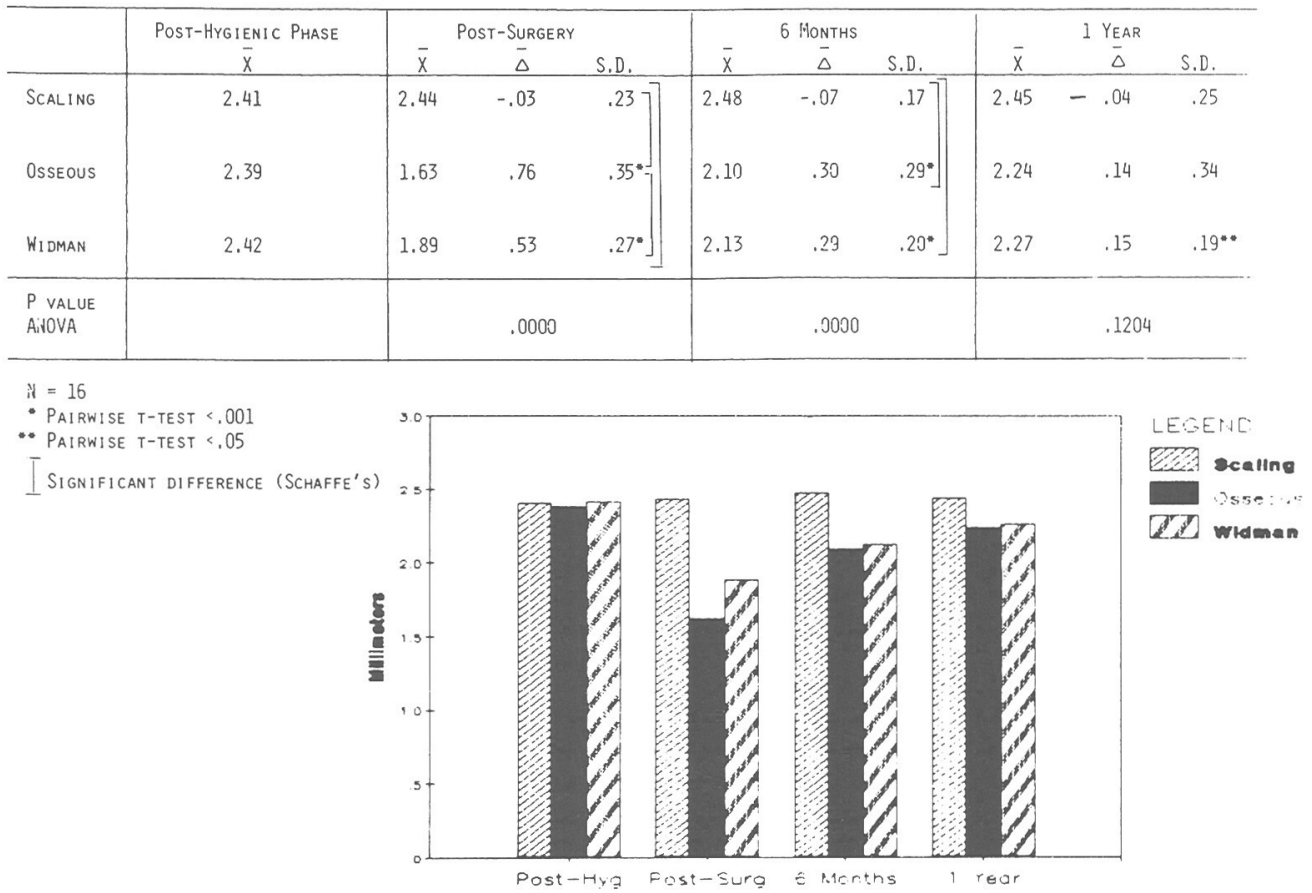

Figure 4. Changes in probing depth from hygienic phase for pockets $1-3 \mathrm{~mm}$.

At each examination the modified Widman significantly reduced pockets in the $1-$ to $3-\mathrm{mm}$ category. At one year, the reduction was significant when compared with posthygiene. When changes between procedures were compared, there were no significant differences among procedures at one year.

Probing Depths (4-6 mm posthygiene). When compared with posthygiene, the scaling, osseous surgery and modified Widman significantly reduced 4- to 6-mm probing depths (Fig. 5). Postsurgery, sites that received osseous surgery had the greatest pocket reduction. Modified Widman sites had greater pocket reduction than scaling. At six months, osseous surgery and the modified Widman significantly reduced pocket depths when compared to scaling. This finding was sustained at the one-year follow-up.

Probing Depths (>7 mm posthygiene). When compared with posthygiene, scaling, osseous surgery and modified Widman significantly reduced pockets in the $>7$-mm category (Fig. 6).

Postsurgery, osseous surgery had significantly greater pocket reduction when compared with scaling. Similarly, osseous surgery achieved greater pocket reduction when compared with the modified Widman. The modified Widman had significantly greater pocket reduction when compared with scaling. At six months, osseous surgery and the modified Widman significantly reduced pockets $>7 \mathrm{~mm}$ when compared to scaling. There were no differences in pocket reduction between osseous surgery and the modified Widman. At one year, osseous surgery and the modified Widman achieved significantly greater pocket reduction when compared with scaling; however, there were no significant differences between osseous surgery and the modified Widman.

Frequency Distribution of Probing Depths (from initial examination to one year). The distribution of sites with different probing depths at different time intervals can be seen in Figure 7. Probing depths for the treatment methods were reduced during the initial preparatory phase of treatment. Posthygiene, there were 238 scaling sites in the 1- to 3-mm category, 197 sites in the 4- to 6-mm range and 15 sites $>7 \mathrm{~mm}$. At one year, there were 310 scaling sites 1 to $3 \mathrm{~mm}, 123$ sites 4 to $6 \mathrm{~mm}$ and 11 sites $7 \mathrm{~mm}$ or greater. Posthygiene, 251 osseous surgery sites were 1 to $3 \mathrm{~mm}, 192$ were 4 to $6 \mathrm{~mm}$ and 13 were $>7 \mathrm{~mm}$. At one year, 381 osseous sites were 1 to $3 \mathrm{~mm}, 74$ sites were 4 to $6 \mathrm{~mm}$, while one site was $>7 \mathrm{~mm}$.

At the posthygiene examination, 231 modified Widman sites were 1 to $3 \mathrm{~mm}, 205$ were 4 to $6 \mathrm{~mm}$ and 26 sites were $>7 \mathrm{~mm}$. At one year, 336 sites were 1 to 3 $\mathrm{mm}, 121$ were 4 to $6 \mathrm{~mm}$ and five sites were $>7 \mathrm{~mm}$.

Attachment Levels (1- to 3-mm pockets posthygienic phase). At each examination there was a significant loss of attachment for the three procedures (Fig. 8). At one year, osseous surgery had significantly greater loss of 


\section{Changes in Probing Depth \\ from Hyglonic Phaso \\ Pockets 4-6 mm}

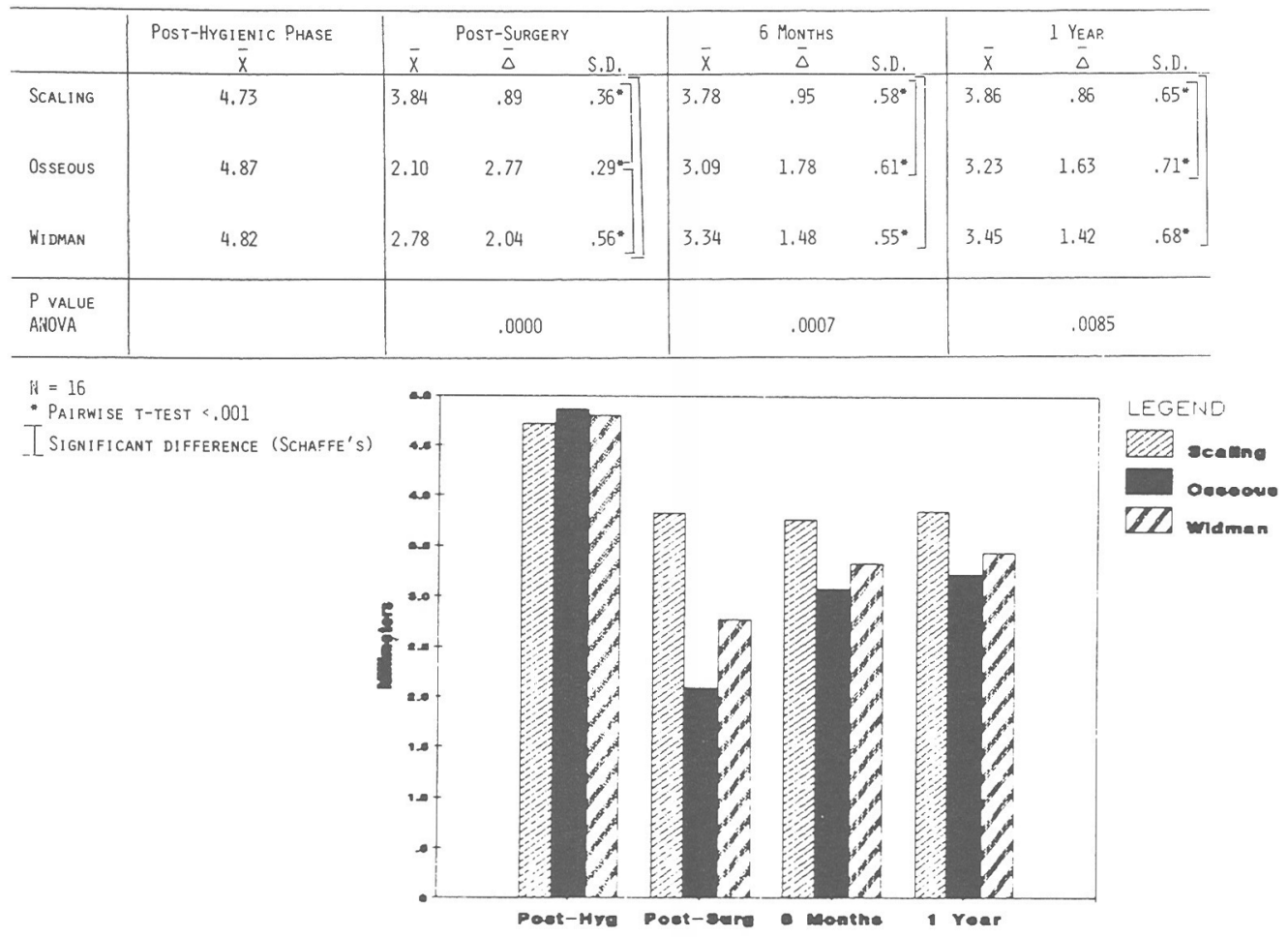

Figure 5. Changes in probing depth from hygienic phase for pockets 4-6 $\mathrm{mm}$.

\section{Changes in Probing Depth \\ from Hyglenic Phase \\ Pockets $7 \mathrm{~mm}$ and Deoper}

\begin{tabular}{|c|c|c|c|c|c|c|c|c|c|c|}
\hline & \multirow{2}{*}{$\begin{array}{l}\text { Post-HYgienic Phase } \\
\overline{\bar{x}}\end{array}$} & \multicolumn{3}{|c|}{ POST-SURGERY } & \multicolumn{3}{|c|}{6 IIONTHS } & \multicolumn{3}{|c|}{1 YEAR } \\
\hline & & $\bar{x}$ & $\bar{\Delta}$ & S.D. & $\bar{x}$ & $\bar{\Delta}$ & S.D. & $\bar{x}$ & $\bar{\Delta}$ & S.D. \\
\hline SCALING & 7.31 & 5.88 & 1.43 & $.47 * * 7$ & 5.55 & 1.75 & $\left..67^{* *}\right]$ & 5.77 & 1.54 & $\left..95^{\circ}\right]$ \\
\hline OSSEOUS & 7.11 & 3.31 & 3.80 & $\left.1.55^{* .}\right\rfloor$ & 4.59 & 2.52 & $\left.1.67^{*}\right\rfloor$ & 4.09 & 3.01 & $1.32 *$. \\
\hline WI DMAN & 7.22 & 3.58 & 3.64 & $\left.1.18^{* *}\right]$ & 4.34 & 2.38 & $\left.1.08^{* *}\right]$ & 4.55 & 2.66 & $1.15^{* *}$ \\
\hline $\begin{array}{l}\text { P value } \\
\text { AilOVA }\end{array}$ & & & .0006 & & & .184 & & & .0396 & \\
\hline
\end{tabular}

is $=16$

- Pairwise t-test <.01

- Pairwise t-test $<001$

I Significant DifFERENCE (SChefFe's)

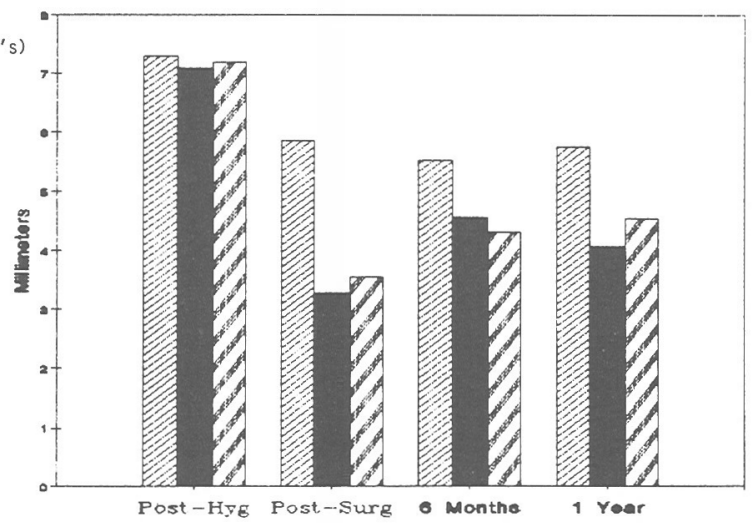

LEGEND 退色 soulins Deseons Wid wan

Figure 6. Changes in probing depth from hygienic phase for pockets $7 \mathrm{~mm}$ and deeper. 
Percentage Distribution of Probing Depths by Treatment At Different Time Intervals

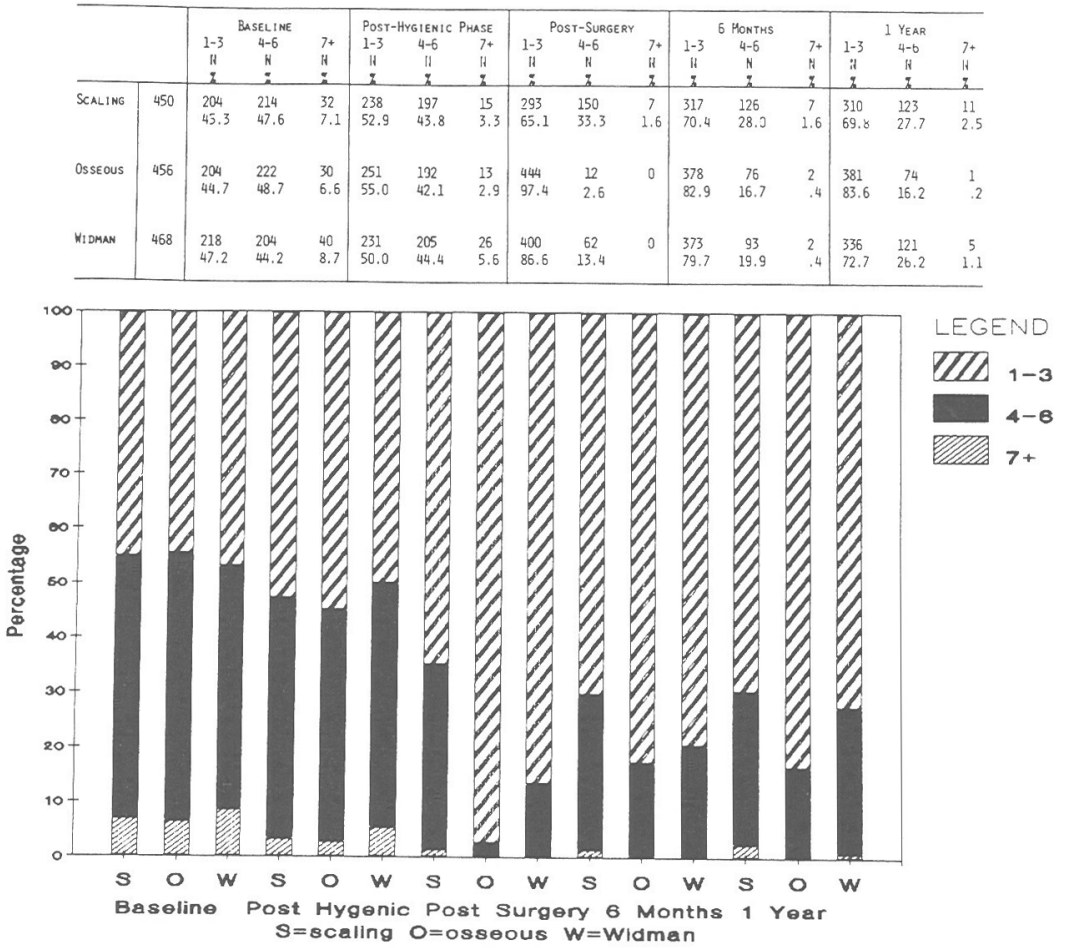

Figure 7. Percentage distribution of probing depths by treatment at different time intervals.

\section{Changes in Attechment Levels from Hyglenic Phase \\ Pockets 1-3 mm}

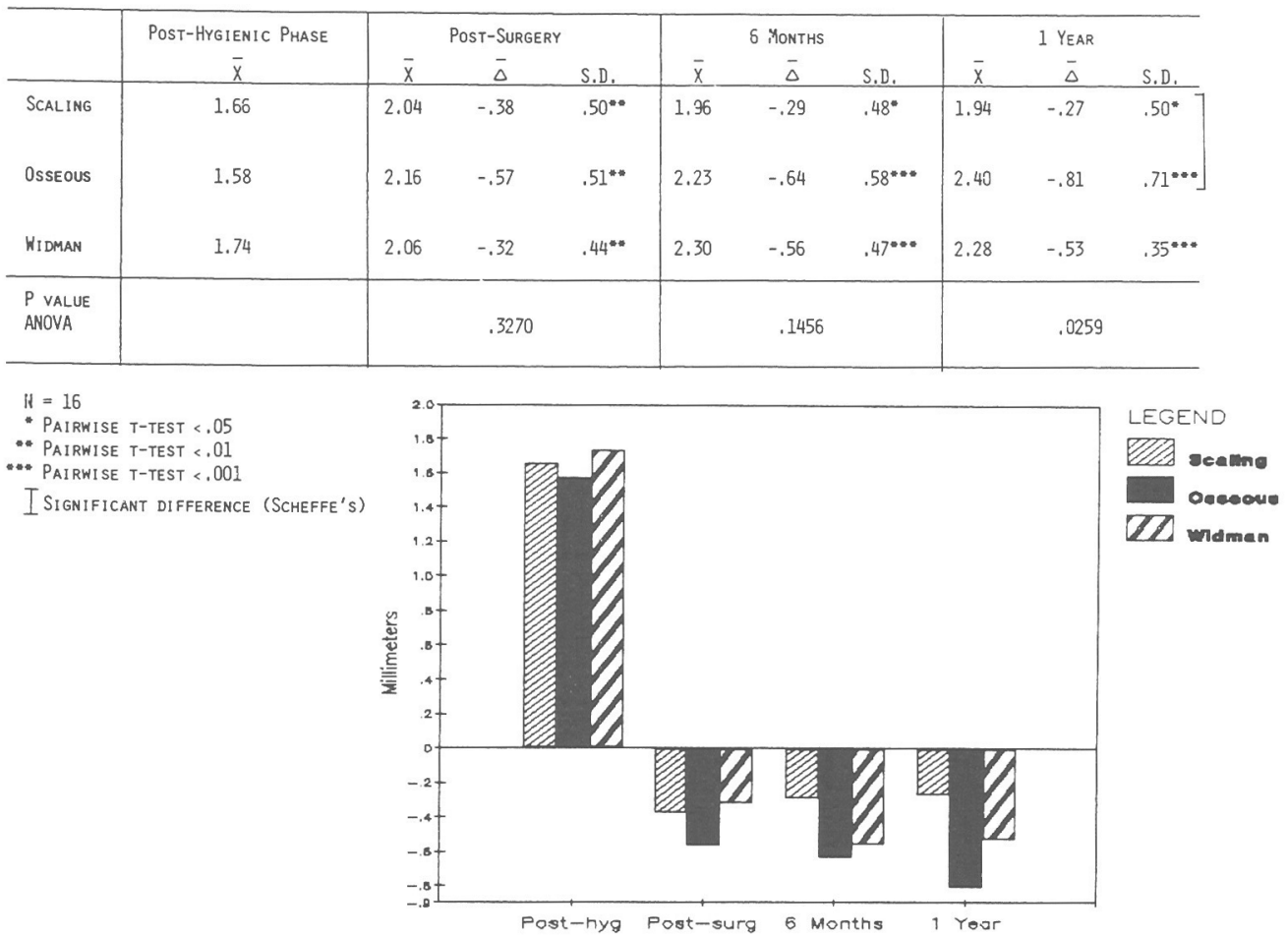

Figure 8. Changes in attachment levels from hygienic phase for pockets $1-3 \mathrm{~mm}$. 
attachment when compared with scaling. The differences in attachment loss between scaling and the modified Widman and between osseous surgery and the modified Widman were not significant.

Attachment Levels (4- to 6-mm pockets posthyigene phase). Scaling had a significant gain in clinical attachment at six months and one year (Fig. 9). Osseous surgery and the modified Widman had significant gains in clinical attachment at six months, but not at one year.

When comparisons were made between the three procedures, no significant differences were noted from postsurgery to one year.

Attachment Levels ( $>7-\mathrm{mm}$ pockets posthygienic phase). Scaling, when compared with baseline, had a significant gain of clinical attachment at the six-month examination (Fig. 10). At each of the other examinations, the gain of attachment, when compared with posthygiene, was not significant. Osseous surgery, when compared with posthygiene, had an insignificant gain of attachment at each examination. The modified Widman, when compared with posthygiene, had a significant gain in clinical attachment postsurgery and at six months. The gain in attachment was not significant at one year. At one year, when gains in attachment were compared among techniques, they were not significant.

Frequency Distribution of Clinical Attachment Levels (from initial examination to one year). Figure 11 shows the frequency distribution of clinical attachment at different time intervals according to the different mo- dalities of treatment. There was a slight gain in attachment for the three procedures after the preparatory phase of treatment. At the posthygiene examination, 239 sites that received scaling had an attachment level gain 0 to $2 \mathrm{~mm}, 193$ sites were in the $3-$ to $5-\mathrm{mm}$ category and 18 sites were $>6 \mathrm{~mm}$. At one year, 259 $(58 \%)$ sites had a clinical attachment level gain of 0 to $2 \mathrm{~mm}, 168(37 \%)$ had a level of 3 to $5 \mathrm{~mm}$ and $17(3 \%)$ had a clinical attachment of $>6 \mathrm{~mm}$.

Posthygiene, 249 sites that received osseous surgery had a clinical attachment level gain of 0 to $2 \mathrm{~mm}, 186$ sites had a level of 3 to $5 \mathrm{~mm}$ and 22 sites had a level $6 \mathrm{~mm}$ or greater. At one year, 231 sites (approximately $50 \%$ ) were in the 0 - to $2-\mathrm{mm}$ range, 183 were 3 to $5 \mathrm{~mm}$ (approximately $40 \%$ ) and 42 were $6 \mathrm{~mm}$ or greater $(9.2 \%)$.

Posthygiene, 212 modified Widman sites had a clinical attachment gain of 0 to $2 \mathrm{~mm}, 221$ sites were in the 3- to 5-mm range and 29 sites were $>6 \mathrm{~mm}$. At one year, 216 sites $(47 \%)$ were in the 0 - to $2-\mathrm{mm}$ category, 195 sites $(42 \%)$ were 3 to $5 \mathrm{~mm}$ and 51 sites (11\%) were $>6 \mathrm{~mm}$.

Interproximal Soft Tissue Changes. Table 1 presents the data related to interproximal flap closure and healing during the six week postoperative period. Complete interproximal flap closure was not achieved following osseous surgery, while complete closure was achieved in 15 sites $(26.8 \%)$ with the modified Widman. From the first postoperative visit through the fifth postoperative week, the modified Widman had a higher per-

\section{Changes in Attachment Levels from Hygienic Phase Pookets $4-6 \mathrm{~mm}$}

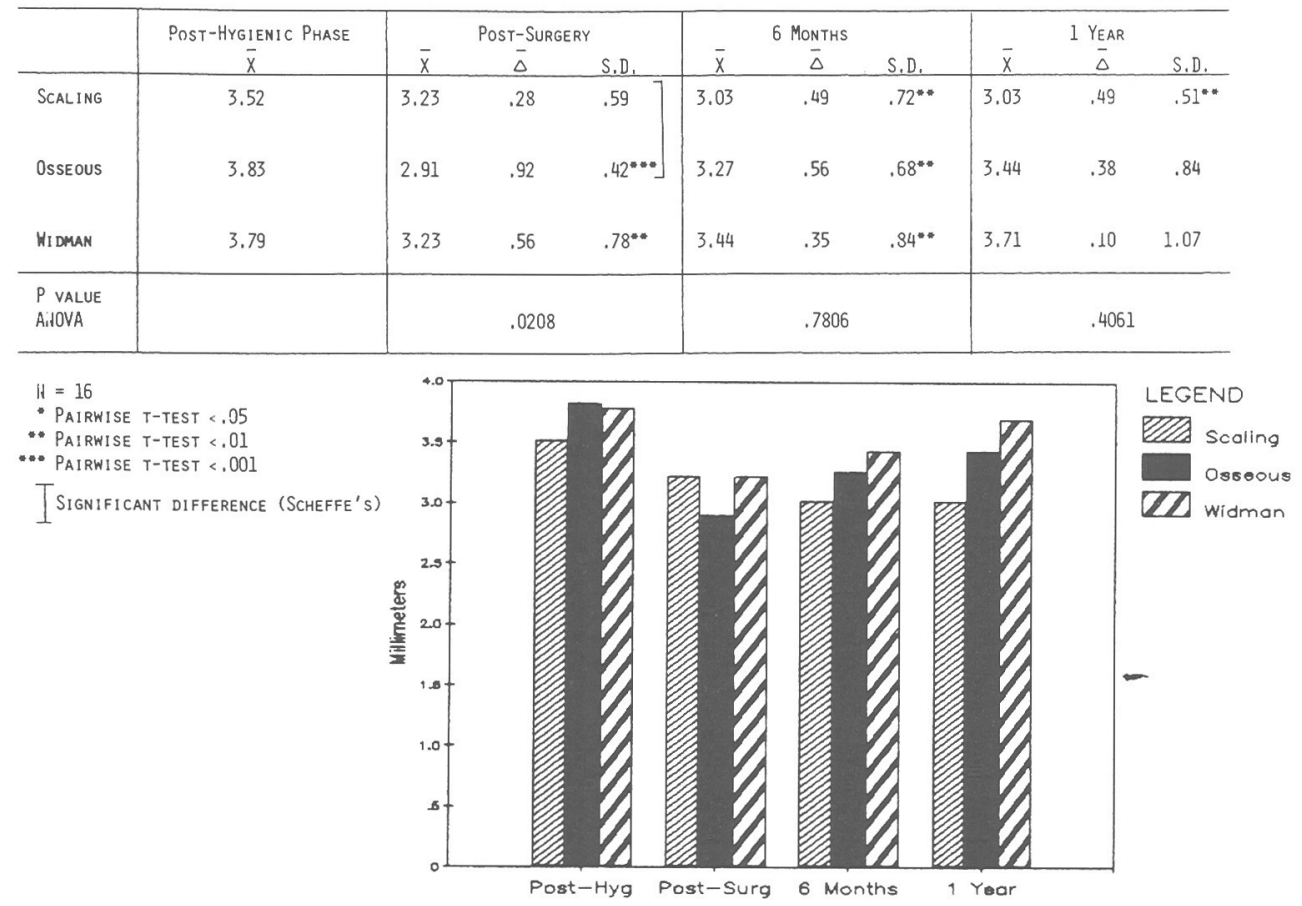

Figure 9. Changes in attachment levels from hygienic phase for pockets 4-6 $\mathrm{mm}$. 
Changes in Attechment Levels from Hygienio Phase

Pookets $7 \mathrm{~mm}$ and Deeper

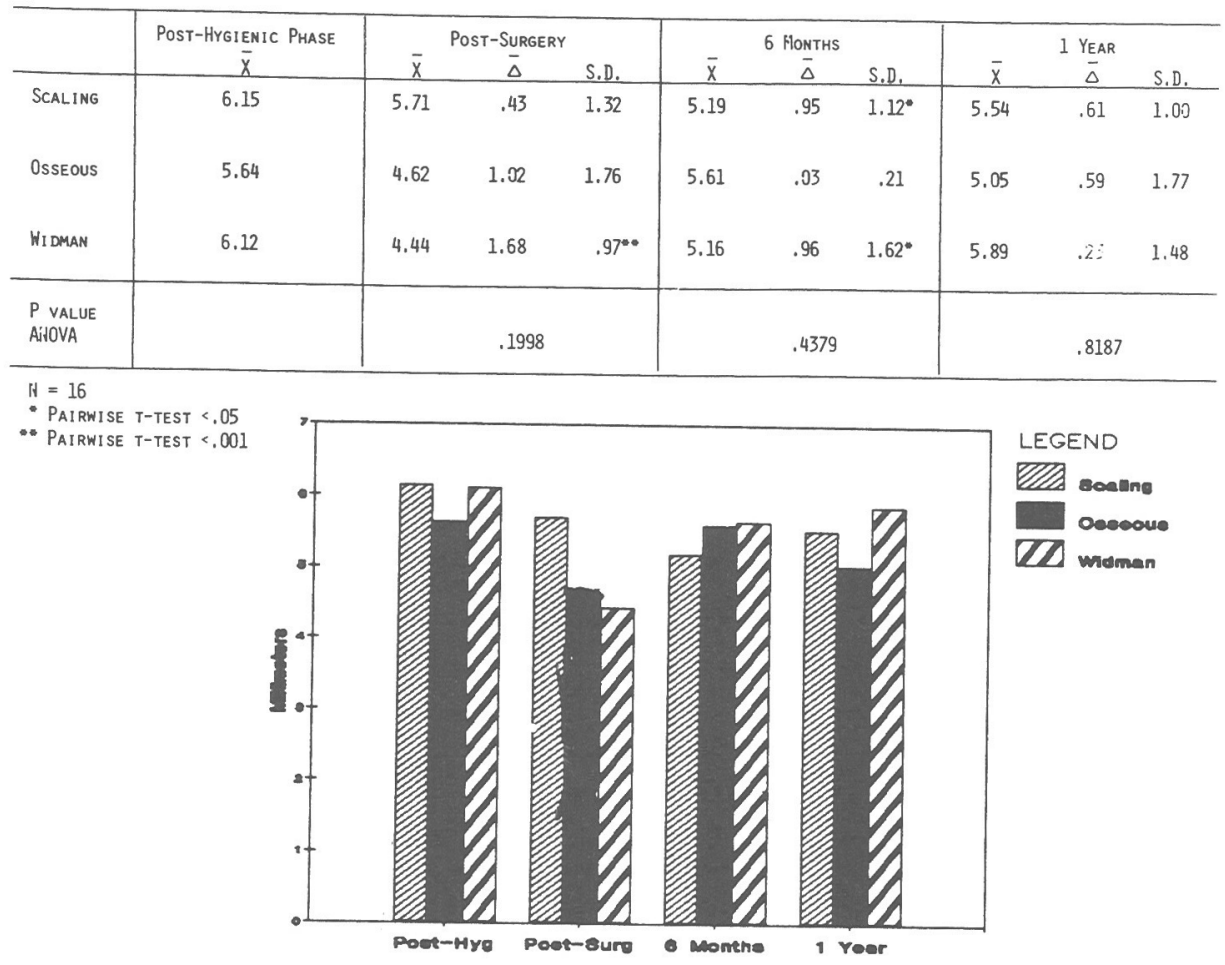

Figure 10. Changes in attachment levels from hygienic phase for pockets $7 \mathrm{~mm}$ and deeper.

\section{Percentage Distribution of Attachment Levels by Treatment At Different Time Intervals}
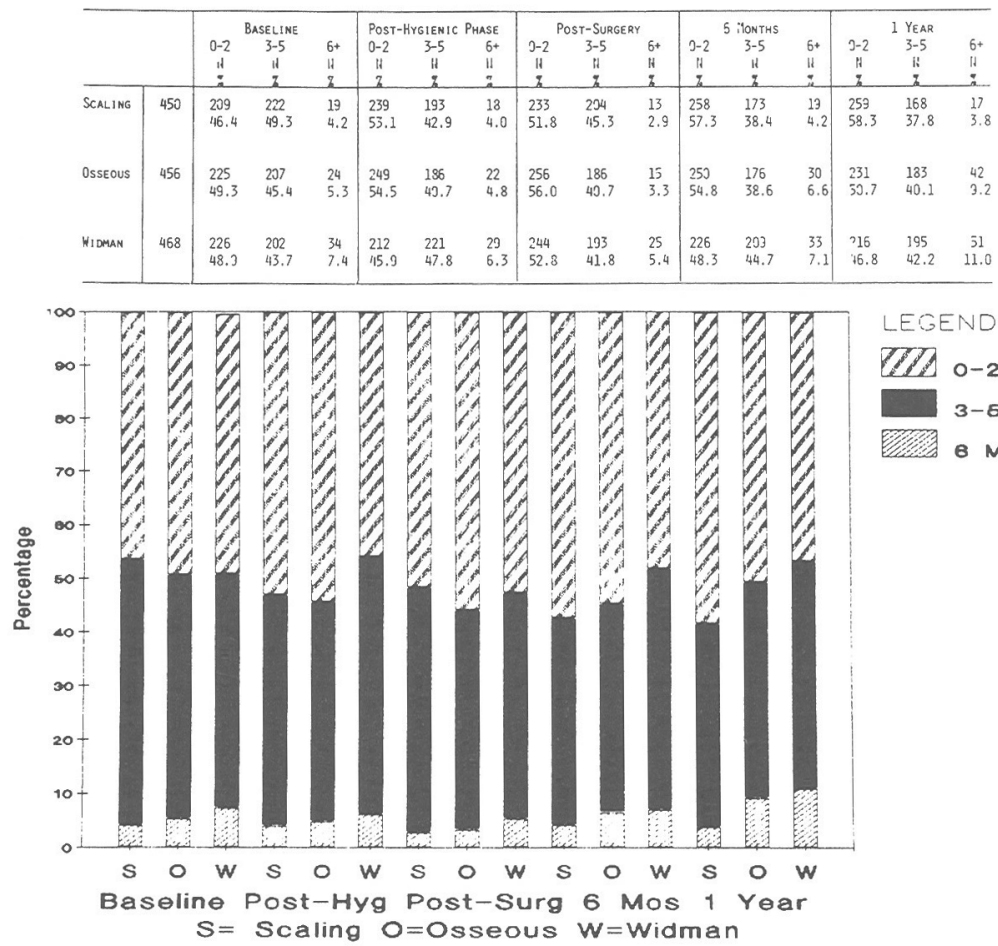

LEGEND Q2D О-2 мм 3-6 MM 症解 $B$ MM +

Figure 11. Percentage distribution of attachment levels by treatment at different time intervals. 
centage of interproximal craters when compared with osseous surgery. At the sixth postoperative week, three interproximal craters were present at sites that received the modified Widman, while there were no soft tissue craters at sites that had osseous surgery.

Table 1

Frequency Distribution of Interproximal Areas Showing Soft Tissue Cratering or Closure after Surgery

\begin{tabular}{|c|c|c|c|c|c|c|c|c|c|c|c|c|c|c|}
\hline & \multicolumn{2}{|c|}{$0 \mathrm{wk}$} & \multicolumn{2}{|c|}{1 wk } & \multicolumn{2}{|c|}{2 wk } & \multicolumn{2}{|c|}{$3 \mathrm{wk}$} & \multicolumn{2}{|c|}{$4 w k$} & \multicolumn{2}{|c|}{5 wk } & \multicolumn{2}{|c|}{6 wk } \\
\hline & CR & $\mathrm{CL}$ & $\mathrm{CR}$ & $\mathrm{CL}$ & CR & $C L$ & $\mathrm{CR}$ & $\mathrm{CL}$ & $\mathrm{CA}$ & $\mathrm{CL}$ & $\mathrm{CR}$ & $\mathrm{CL}$ & $\mathrm{CF}$ & $\mathrm{CL}$ \\
\hline $\begin{array}{l}\text { Osseous } \\
\text { Surgery }\end{array}$ & 57 & 0 & 35 & 22 & 20 & 37 & 13 & 44 & 5 & 52 & 3 & 64 & 0 & 57 \\
\hline $\begin{array}{l}\text { Widman } \\
\text { Surgery }\end{array}$ & 41 & 15 & 41 & & 30 & 26 & 26 & 30 & & & & & & 53 \\
\hline $\mathrm{P}^{*}$ & & & & & & & & & & 09 & & 82 & & 184 \\
\hline
\end{tabular}

Recession (pockets 1 to $3 \mathrm{~mm}$ posthygiene). When compared with posthygiene, the scaling, osseous surgery and the modified Widman had significant recession at each examination (Table 2 ).

When recession was compared among procedures, postsurgery osseous surgery and the modified Widman had significantly greater recession than scaling. Osseous surgery had greater recession when compared with the modified Widman. At six months, osseous surgery and the modified Widman had greater recession than scaling. This finding was sustained at one year.

Recession (pockets 4 to $6 \mathrm{~mm}$ posthygiene). Between posthygiene and one year, there was significant recession for each procedure (Table 2). When recession was compared between procedures, osseous surgery and the modified Widman had significantly greater recession than scaling. There were no significant differences in

Table 2

Recession Levels from Hygienic Phase to one Year for Pockets 1-3, 4-6 and $7 \mathrm{~mm}$ and Greater

\begin{tabular}{|c|c|c|c|c|c|c|c|c|c|c|}
\hline \multicolumn{11}{|c|}{$\begin{array}{l}\text { Recession Levels from Hrgienic Prase } \\
\text { fuckets } 1-3 \text { mm. }\end{array}$} \\
\hline & \multirow{2}{*}{$\begin{array}{c}\text { Post-HrgienIC PHASE } \\
\overline{\mathrm{X}} \\
\end{array}$} & \multicolumn{3}{|c|}{ POST-SURGERY } & \multicolumn{3}{|c|}{6 MONTHS } & \multicolumn{3}{|c|}{1 YeAR } \\
\hline & & $\bar{x}$ & $\dot{\Delta}$ & S.D. & $\bar{x}$ & $\bar{\Delta}$ & S.D. & $\bar{x}$ & $\bar{\Delta}$ & S.D. \\
\hline SCALING & .74 & .39 & .35 & $\left..33^{*} 7\right]$ & .50 & .23 & $\left..37^{\circ} 7\right]$ & .50 & .24 & $\left..46^{\circ}\right]$ \\
\hline Osseous & .80 & -.52 & 1.32 & $.46 \cdots$ & -.13 & .93 & $.59 \cdot$. & -.15 & .95 & $.58 * *$ \\
\hline Hionan & $.6 ?$ & -.17 & .84 & $\left..44^{* *}\right]$ & -.17 & .84 & $.46 *]$ & .01 & .66 & $.40^{\circ}$ \\
\hline $\begin{array}{l}\text { P value } \\
\text { AnOVA }\end{array}$ & & & .0000 & & & .0003 & & & .0007 & \\
\hline
\end{tabular}

$N=16$

- Palrmise t-test < .05

- Patrmise t-test $<.001$

ISIGNificany difference (SCheffe's) Pockets 4-6 m.

\begin{tabular}{|c|c|c|c|c|c|c|c|c|c|c|}
\hline & \multirow{2}{*}{$\begin{array}{l}\text { Post-HirglentC Phase } \\
\bar{x} \\
\end{array}$} & \multicolumn{3}{|c|}{ POST-SURGERY } & \multicolumn{3}{|c|}{6 MONTHS } & \multicolumn{3}{|c|}{$1 Y_{\text {EAR }}$} \\
\hline & & $\bar{x}$ & $\bar{\Delta}$ & S.D. & $\bar{x}$ & $\bar{\Delta}$ & S.0. & $\bar{x}$ & $\bar{\Delta}$ & S.D. \\
\hline SCALING & 1.20 & .60 & .60 & $\left..47^{*} 7\right]$ & .75 & .44 & $\left..58^{\circ}\right]$ & .82 & .37 & $\left..48^{\circ}\right]$ \\
\hline Osseous & 1.04 & -.80 & 1.84 & $.52 * 01$ & -.18 & 1.22 & $.61 * *]$ & -.21 & 1.25 & $.59 * 0$ \\
\hline WIDMAN & 1.02 & -.45 & 1.47 & $\left..66^{* \bullet}\right]$ & -.13 & 1.12 & $.63^{\circ 0}$ & -.03 & 1.05 & $.59 * 0$ \\
\hline $\begin{array}{l}\text { P value } \\
\text { AilOVA }\end{array}$ & & \multicolumn{3}{|c|}{.0000} & \multicolumn{3}{|c|}{.0014} & \multicolumn{3}{|c|}{.0002} \\
\hline \multicolumn{11}{|c|}{$\begin{array}{l}11=16 \\
\text { PAIRWISE T-TEST }<.05 \\
\because \text { PAIRWISE T-TEST }<.001\end{array}$} \\
\hline
\end{tabular}

Recession Levels from Hrgienic Phase POCKETS 7 MM. AND DEEPER

\begin{tabular}{|c|c|c|c|c|c|c|c|c|c|c|}
\hline & \multirow{2}{*}{$\begin{array}{c}\text { Post-HYgienic Phase } \\
\bar{x} \\
\end{array}$} & \multicolumn{3}{|c|}{ POST-SURGery } & \multicolumn{3}{|c|}{5 MONTHS } & \multicolumn{3}{|c|}{ I YeAR } \\
\hline & & $\bar{x}$ & $\bar{\Delta}$ & S.D. & $\bar{x}$ & $\bar{\Delta}$ & S.D. & $\bar{x}$ & $\bar{\Delta}$ & S.D. \\
\hline SCALING & 1.15 & .16 & .98 & $\left.1.01^{\circ}\right]$ & .35 & .80 & $\left..97^{\circ}\right]$ & .23 & .92 & $.99^{\circ}$ \\
\hline OSSEOUS & 1.46 & -1.31 & 2.77 & $.83 * 01$ & -1.01 & 2.48 & $1.38^{\circ \circ}$ & -.96 & 2.42 & $91^{* *}$ \\
\hline WLDMAN & 1.07 & -.86 & 1.94 & $.67 \times .4]$ & -.82 & 1.89 & $.88^{\circ * *}$ & -.76 & 1.83 & $.84^{* *}$ \\
\hline $\begin{array}{l}\text { P VALUE } \\
\text { AiNOVA }\end{array}$ & & & .0010 & & & .014 & & & .0092 & \\
\hline
\end{tabular}


recession when osseous surgery and the modified Widman were compared.

Recession (pockets $>7 \mathrm{~mm}$ posthygiene). When compared with posthygiene, the three procedures had a statistically significant amount of recession (Table 2).

Postsurgery, osseous surgery and the modified Widman had significantly greater recession than scaling. When osseous surgery and the modified Widman were compared, recession for osseous surgery was greater than for the modified Widman.

At six months osseous surgery and the modified Widman had significantly greater recession than scaling. When osseous surgery and the modified Widman were compared, there was no statistical difference. These findings were similar at one year.

The frequency distribution for recession at different examination intervals can be seen in Table 3. Posthygiene, the gingival margins for the three procedures were above the cementoenamel junctions. At one year $62 \%$ of scaling sites had the gingival margin coronal to the cementoenamel junction. The percentage was less for osseous surgery $(31.8 \%)$ and the modified Widman (38.5\%). Osseous surgery had the highest percentage of recession in the $0-$ to $1-\mathrm{mm}$ range $(43.2 \%)$ and in the $3-\mathrm{mm}$ and greater range $(2.2 \%)$. Osseous surgery (22.8\%) and modified Widman (23.4\%) had similar recession in the $2-$ to $3-\mathrm{mm}$ range.

\section{DISCUSSION}

The results indicate that at one year scaling, osseous surgery and the modified Widman procedure were effective in treating moderate to advanced adult periodontitis. The effectiveness of treatment was based on reduction of gingival inflammation and bacterial deposits and improvements in probing depth and clinical attachment levels. The nonsurgical and surgical procedures produced minimal posttreatment recession.

For statistical purposes the patient was used as the statistical unit. Changes in gingival inflammation, plaque, probing depth attachment levels and recession were based on patient means. Lindhe and Nyman ${ }^{21}$ have questioned the use of patient means for analyzing data from longitudinal studies. Subtle changes at specific sites are masked when patient means are used for data analysis. Recently, the importance of using the patient as the statistical unit has been clarified. ${ }^{22} \mathrm{We}$ feel the use of frequency distributions for individual sites can provide important additional information relating to changes within the study population.

Lindhe and Nyman ${ }^{4}$ and Rosling et al. ${ }^{5}$ have reported on the importance of posttreatment oral hygiene and maintenance of oral health. In this study, at one year the gingival and plaque scores were significantly reduced when compared with the initial examination. The patients were seen every three months for periodontal maintenance therapy.

Shallow pockets $(1-3 \mathrm{~mm})$ were reduced by the three procedures. At one year 1- to 3-mm pockets were significantly reduced from posthygiene by the modified Widman. Postsurgery, 4- to 6-mm pockets were significantly reduced by the three procedures. Hill et al. ${ }^{7}$ reported similar findings for 4- to 6-mm pockets. In the Hill study, at one year, pocket elimination and the modified Widman achieved significantly greater reduction when compared with curettage or scaling. At one year, Philstrom et al. ${ }^{9}$ reported greater pocket reduction with the modified Widman than with scaling alone.

Pockets that were $7 \mathrm{~mm}$ or greater at posthygiene were significantly reduced by scaling, osseous surgery and the modified Widman procedures. At each examination osseous surgery and the modified Widman achieved significantly greater pocket reduction than scaling. At one year, pocket reduction for osseous surgery $(3.01 \mathrm{~mm})$ was almost twice as great as scaling $(1.54 \mathrm{~mm})$. At one year, Hill et al. ${ }^{7}$ reported the greatest pocket reduction for pocket elimination procedures, although curettage, scaling and the modified Widman were significantly different when compared with baseline. In the Pihlstrom study, ${ }^{9}$ scaling and root planing successfully reduced pockets $7 \mathrm{~mm}$ or greater. The addition of the modified Widman to scaling demonstrated greater pocket reduction for the surgical procedure. These differences tended to diminish over a fouryear period. At one year the differences in pocket

Table 3

Frequence Distribution of Different Levels of Recession at Different Time Intervals

\begin{tabular}{|c|c|c|c|c|c|c|c|c|c|c|c|c|c|c|c|c|c|c|c|c|c|}
\hline & \multicolumn{4}{|c|}{ BASELINE } & \multicolumn{4}{|c|}{ Post-Hrgienic Phase } & \multicolumn{4}{|c|}{ POST-SURGERY } & \multicolumn{4}{|c|}{6 ، IONTHS } & \multicolumn{4}{|c|}{1 YEAR } \\
\hline & & + & $0 /-1$ & $-2 /-3$ & $-3+$ & + & $0 /-1$ & $-2 /-3$ & $-3+$ & + & $0 /-1$ & $-2 /-3$ & $-3+$ & + & $0 /-1$ & $-2 /-3$ & $-3+$ & + & $0 /-1-$ & $2 /-3$ & $-3+$ \\
\hline & & $\begin{array}{l}11 \\
8\end{array}$ & $\begin{array}{l}N \\
7\end{array}$ & $\begin{array}{l}N \\
N\end{array}$ & $\begin{array}{l}N \\
\%\end{array}$ & $\begin{array}{l}\text { in } \\
\%\end{array}$ & $\begin{array}{l}N \\
\%\end{array}$ & If & $\begin{array}{l}\text { N } \\
\%\end{array}$ & II & $\begin{array}{l}\text { if } \\
\%\end{array}$ & in & $\begin{array}{l}\text { N } \\
\%\end{array}$ & II & $\begin{array}{l}\vdots 1 \\
\%\end{array}$ & in & $\begin{array}{l}\text { if } \\
\%\end{array}$ & $\begin{array}{l}N \\
\%\end{array}$ & $\begin{array}{l}\text { II } \\
\%\end{array}$ & li & $\begin{array}{l}\text { If } \\
\%\end{array}$ \\
\hline SCA $-1 N_{0}$ & 450 & $\begin{array}{l}372 \\
82.7\end{array}$ & $\begin{array}{c}62 \\
13.8\end{array}$ & $\begin{array}{l}16 \\
3.6\end{array}$ & 0 & $\begin{array}{l}364 \\
80.9\end{array}$ & $\begin{array}{c}69 \\
15.3\end{array}$ & $\begin{array}{r}15 \\
3.3\end{array}$ & $\begin{array}{r}2 \\
.4\end{array}$ & $\begin{array}{l}262 \\
58.2\end{array}$ & $\begin{array}{l}143 \\
32.9\end{array}$ & $\begin{array}{l}40 \\
8.9\end{array}$ & 0 & $\begin{array}{l}288 \\
64.0\end{array}$ & $\begin{array}{l}137 \\
30.4\end{array}$ & $\begin{array}{r}23 \\
5.1\end{array}$ & $\begin{array}{r}2 \\
.4\end{array}$ & $\begin{array}{l}276 \\
62.2\end{array}$ & $\begin{array}{l}138 \\
31.1\end{array}$ & $\begin{array}{l}29 \\
6.5\end{array}$ & $\begin{array}{l}1 \\
.2\end{array}$ \\
\hline OSsEcus & 456 & $\begin{array}{l}377 \\
82.7\end{array}$ & $\begin{array}{c}54 \\
11.8\end{array}$ & $\begin{array}{l}25 \\
5.5\end{array}$ & 0 & $\begin{array}{l}384 \\
84.2\end{array}$ & $\begin{array}{l}45 \\
9.9\end{array}$ & $\begin{array}{r}27 \\
5.9\end{array}$ & 0 & $\begin{array}{c}58 \\
12.7\end{array}$ & $\begin{array}{l}204 \\
44.7\end{array}$ & $\begin{array}{l}184 \\
40.4\end{array}$ & $\begin{array}{l}10 \\
2.2\end{array}$ & $\begin{array}{l}145 \\
31.8\end{array}$ & $\begin{array}{l}212 \\
46.5\end{array}$ & $\begin{array}{r}38 \\
19.3\end{array}$ & $\begin{array}{r}11 \\
2.4\end{array}$ & $\begin{array}{l}145 \\
31.8\end{array}$ & $\begin{array}{l}197 \\
43.2\end{array}$ & $\begin{array}{l}104 \\
22.8\end{array}$ & $\begin{array}{l}10 \\
2 . \hat{\imath}\end{array}$ \\
\hline WIDiAai: & 468 & $\begin{array}{l}363 \\
73.6\end{array}$ & $\begin{array}{c}73 \\
15.8\end{array}$ & $\begin{array}{l}26 \\
5.6\end{array}$ & 0 & $\begin{array}{l}347 \\
75.1\end{array}$ & $\begin{array}{c}80 \\
17.3\end{array}$ & $\begin{array}{r}35 \\
7.6\end{array}$ & 0 & $\begin{array}{l}106 \\
22.9\end{array}$ & $\begin{array}{l}205 \\
44.4\end{array}$ & $\begin{array}{l}150 \\
32.5\end{array}$ & $\begin{array}{l}1 \\
.2\end{array}$ & $\begin{array}{l}110 \\
23.5\end{array}$ & $\begin{array}{l}250 \\
53.4\end{array}$ & $\begin{array}{l}107 \\
22.9\end{array}$ & $\begin{array}{l}1 \\
.2\end{array}$ & $\begin{array}{l}178 \\
38.5\end{array}$ & $\begin{array}{l}174 \\
37.7\end{array}$ & $\begin{array}{l}108 \\
23.4\end{array}$ & $\begin{array}{l}2 \\
.4\end{array}$ \\
\hline
\end{tabular}


reduction between scaling alone and scaling and the modified Widman was slightly less than $1 \mathrm{~mm}$. In this study the difference between scaling and the modified Widman was $1.2 \mathrm{~mm}$, and the difference between scaling and osseous surgery was $1.47 \mathrm{~mm}$. The differences between our study and the Pihlstrom study tend to indicate that scaling together with osseous surgery will produce greater pocket reduction than scaling alone. Scaling together with the modified Widman will also produce significantly shallower probing depth for up to a year.

Analysis of frequency distributions may aid in evaluating changes that occurred at the various probing depths. This study attempted to exclude healthy sites by treating more involved posterior quadrants. Vertical releasing incisions were used in order to avoid including uninvolved teeth. With efforts to avoid treating healthy sites at the posthygiene phase, $50 \%$ to $55 \%$ of all treated sites were in the 1 - to $3-\mathrm{mm}$ range. Knowles et al. ${ }^{6}$ have discussed the problem of including too many healthy sites in longitudinal studies. Excessive healthy sites can mask changes in patient means. Consequently, inclusion of frequency distribution data can be meaningful in analyzing changes that occur as a result of treatment.

At one year there was an increase in the percentage of 1- to 3-mm probing depths for scaling (70\%), osseous surgery $(83.6 \%)$ and modified Widman $(72 \%)$. At one year, sites treated by osseous surgery had the fewest sites in the 4- to 6-mm range (16.2\%). Scaling and the modified Widman had higher percentages of sites 4 to $6 \mathrm{~mm}$ (26.2\%). Initially, 32 scaling sites, 40 modified Widman sites and 30 osseous were $7 \mathrm{~mm}$ or greater. At one year 11 scaling sites, five modified Widman sites and only one osseous surgery site remained in this category. Lindhe and Nyman ${ }^{21}$ reported $92 \%$ to $99 \%$ of all treated sites less than $4 \mathrm{~mm}$ at the end of 14 years of maintenance. One per cent of all sites remained greater than $6 \mathrm{~mm}$. This successful reduction in probing depths was related to high patient compliance with plaque removal and frequent professional scalings. Attachment level changes for 1- to 3-mm probing depths were similar to those reported by Hill et al., ${ }^{7}$ Pihlstrom et al. ${ }^{9}$ and Lindhe et al. ${ }^{23}$ These studies indicated that attachment loss occurred for treatment of shallow pockets regardless of the type of treatment performed. Lindhe et al. ${ }^{24}$ have suggested that instrumentation of shallow crevices with local anesthesia may sever the transseptal fibers thereby allowing for apical migration of the junctional epithelium. The loss of connective tissue attachment following root planing may explain the clinical attachment loss measured after treatment.

There was an increase in clinical attachment levels for 4- to 6-mm pockets from postsurgery to one year. This increase occurred for the three methods of treatment. Our findings differ from those reported by Rosling et al. ${ }^{5}$ and Hill et al. ${ }^{7}$ Rosling compared various surgical treatments over two years. The greatest loss of attachment occurred on the buccal surfaces $(1.5 \mathrm{~mm})$ of areas treated with apically positioned flaps and osseous surgery. Hill et al. ${ }^{7}$ reported a decrease in clinical attachment for osseous surgery $(0.17 \mathrm{~mm})$ and modified Widman $(0.02 \mathrm{~mm})$ at one year. This amount of attachment loss would appear to have no clinical significance.

Attachment level changes for pockets $7 \mathrm{~mm}$ and greater indicated an increase in clinical levels for the three procedures. There were no significant differences from posthygiene to one year, and there were no differences among the procedures. Hill et al. $^{7}$ and Lindhe et al. ${ }^{10}$ reported gains in clinical attachment for deep pockets, and these gains occurred for the various methods of treatment. In the Hill study pocket elimination, curettage, scaling and the modified Widman had significant gains in attachment when compared with the hygienic phase. When the procedures were compared, there were no significant differences between them.

The frequency distribution for clinical attachment levels from 0 to $2 \mathrm{~mm}$ indicated a loss of attachment for shallow pockets treated by scaling and osseous surgery. At one year the modified Widman had a slight increase in the number of $0-$ to 2-mm sites when compared with posthygiene. For the three methods of treatment, there was an increase in the number of sites in the 3- to 5-mm range. At one year, for $6 \mathrm{~mm}$ and greater attachment levels, scaling and osseous surgery had the fewest sites remaining in this category.

Most longitudinal studies have not reported changes in gingival recession as a result of therapy. ${ }^{1-7,9-13}$ Isidor et al. ${ }^{25}$ reported gingival recession in a six-month study comparing the modified Widman flap, the apically positioned flap and scaling and root planing. Osseous surgery was not performed. $\mathrm{He}$ reported $2.5 \mathrm{~mm}$ of recession for the surgical procedures and $1.8 \mathrm{~mm}$ of recession for scaling and root planing. The differences between the surgical procedures and scaling were statistically significant. There were no changes in gingival recession between the three-month and sixmonth examinations.

In this study, for 1- to 3-mm pockets, the three methods of treatment produced significant gingival recession when compared with posthygiene. When the procedures were compared at one year, osseous surgery and the modified Widman had significantly greater recession than scaling. At one year there was significant recession for 4- to 6-mm pockets for the three modalities of therapy. Furthermore, osseous surgery and the modified Widman had greater recession than scaling alone. Similar findings were found for pockets $7 \mathrm{~mm}$ or greater.

In general, postsurgery, there was soft tissue rebound for sites treated with osseous surgery. For sites treated with the modified Widman, there was slight soft tissue rebound at six months, followed by slight recession at one year. 
Recently, it has been suggested that periodontal healing as a result of definitive therapy is complete at six months. ${ }^{26}$ The result of changes in gingival recession suggests that these changes continue for at least a year. Clinical observation as a result of studying the postoperative photographs suggests that for osseous surgery gingival recession is initially achieved by positioning the flaps apically. The gingival margins remained stable on the palatal aspect of maxillary first molars and moved coronally on the second molar and first and second bicuspids. This phenomenon may be related to tooth position and anatomy. The palatal root of the maxillary second molar is usually parallel to the long axis of the tooth, while the palatal root of the first molar flares toward the midline. The roots of the maxillary second and first bicuspids tend to be parallel to the long axis of the tooth. The variation in angulation of these teeth may be related to the stability of the gingival margins after surgery.

Many clinicians avoid performing modified Widman surgical procedures because soft tissue craters occur after surgery. This study documented the difficulty in achieving primary flap closure after modified Widman surgery. Complete closure was achieved in 15 out of 56 interproximal sites $(26.8 \%)$, while complete closure of osseous surgery sites was not achieved. Craters were measured over six weeks. There was a tendency for sites that received the modified Widman therapy to have a higher percentage of craters during healing. However, at six weeks there were no meaningful differences between the two surgical procedures.

Studies such as this have certain inherent problems. One problem is long-term identification of measurement reference points. The most frequently used reference point was the cementoenamel junction. With frequent coronal polishing, seven measurement points could not be identified at the six-month examination. At one year, 17 measurement points could no longer be identified. Measurements from these areas were approximated. Ideally, a larger sample size would have been desirable. Increasing the sample size would, however, make control of recall appointments difficult. Large study populations require that treatment and follow-up visits be done over an extended time. Varying time intervals for treatment may impact data since it could be months between the time the first and last patients were treated.

It has been over 20 years since the concept of attachment level measurements was introduced. ${ }^{27}$ The importance of monitoring attachment levels as the standard for measuring change between varying time intervals cannot be ignored. There is a difference of opinion, however, between the researcher and the clinician when the significance of clinical attachment level measurements is compared with probing depth changes. The practicing periodontist and general dentist more often relate to changes in probing depth because residual pockets have to be maintained by the patient, hygienist and clinician. Consequently, many clinicians attempt to reduce probing depth with surgery. In this clinical study scaling was somewhat effective at reducing pocket depth; however, it was not as effective as the surgical procedures.

\section{REFERENCES}

1. Ramfjord, S. P., Nissle, R. R., Schick, A., and Cooper, H.: Subgingival curettage versus surgical elimination of periodontal pockets. J Periodontol 39: 167, 1968.

2. Ramfjord, S. P., Knowles, J. W., Nissle, R. R., et al.: Longitudinal study of periodontal therapy. J Periodontol 44: 66, 1973.

3. Ramfjord, S. P., Knowles, J. W., Nissle, R. R., et al.: Results following three modalities of periodontal therapy. $J$ Periodontol 46: $522,1975$.

4. Lindhe, J., and Nyman, S.: The effect of plaque control and surgical pocket elimination on the establishment and maintenance of periodontal health. A longitudinal study of periodontal therapy in cases of advanced disease. J Clin Periodontol 2: 67, 1975.

5. Rosling, B., Nyman, S., Lindhe, J., and Barbro, J.: The healing potential of the periodontal tissues following different techniques of periodontal surgery in plaque free dentitions. A 2-year study. $J$ Clin Periodontol 3: 233, 1976.

6. Knowles, J. W., Burgett, F. G., Nissle, R. R., et al.: Results of periodontal treatment related to pocket depth and attachment level. Eight years. J Periodontol 50: 225, 1979.

7. Hill, R. W., Ramfjord, S. P., Morrison, E. C., et al.: Four types of periodontal treatment compared over two years. J Periodontol 52: $655,1981$.

8. Smith, J. D., Ammons, W. F., and Van Belle, G.: A longitudinal study of periodontal status comparing osseous recontouring with flap curettage. I. Results after 6 months. J Periodontol 51: 367, 1980.

9. Pihlstrom, B. L., Ortiz-Campos, C., and McHugh, R. B.: A randomized four-year study of periodontal therapy. J Periodontol 52: 1981.

10. Lindhe, J., Westfelt, E., Nyman, S., et al.: Long-term effect of surgical/non-surgical treatment of periodontal disease. J Clin Periodontol 11: 448, 1984.

11. Hirschfeld, L., and Wasserman, B.: A long-term survey of tooth loss in 600 treated periodontal patients. $J$ Periodontol 49: 225, 1978.

12. McFall, W. T.: Tooth loss in 100 treated patients with periodontal disease. J Periodontol 53: 539, 1982.

13. Becker, W., Berg, L., and Becker, B. E.: The long-term evaluation of periodontal treatment and maintenance in 95 patients. Int J Periodontol Restor Dent 2: 55, 1984.

14. Ramfjord, S. P., and Nissle, R. R.: The modified Widman flap. J Periodontol 46: 522, 1975.

15. Ochsenbein, C.: A primer for osseous surgery. Int J Periodontol Restor Dent 1: 78, 1986.

16. Löe, H., and Silness, J.: Periodontal disease in pregnancy. I. Prevalence and severity. Acta Odontol Scand 21: 533, 1963.

17. Silness, J., and Löe, H.: Periodontal disease in pregnancy. II. Correlation between oral hygiene and periodontal condition. Acta Odontol Scand 22: 121, 1964.

18. Glickman, I.: Clinical Periodontology, ed 2, pp 694-696. Philadelphia, W. B. Saunders Co, 1958.

19. Glickman, I.: Clinical Peridontology, ed 2, pp 473. Philadelphia, W. B. Saunders Co, 1958.

20. Tibetts, L., Ochsenbein, C., and Laughlin, D. M.: Rationale for the lingual approach to mandiblar osseous surgery. Dent Clin No Am pp 61-78, Philadelphia, W. B. Saunders Co, 1976.

21. Lindhe, J., and Nyman, S.: Long-term maintenance of patients treated for advanced periodontal disease. J Clin Periodontol 11: 504, 1984.

22. Imrey, P. B.: Considerations in the statistical analysis of clinical trials in periodontitis. J Clin Periodontol 13: 817, 1986. 
23. Lindhe, J., Socransky, S. S., Nyman, S., et al.: Critical probing depths in periodontal therapy. J Clin Periodontol 9: 323, 1982.

24. Lindhe, J., Nyman, S., and Karring, T.: Scaling and root planing in shallow pockets. J Clin Periodontol 9: 415, 1982.

25. Isidor, F., Karring, T., and Attstrom, R.: The effect of root planing as compared to that of surgical treatment. J Clin Periodontol 11: $669,1984$.

26. Westfelt, L., Bragd, S. S., Socransky, A. D., et al.: Improved periodontal conditions following therapy. J Clin Periodontol 12: 283, 1985 .

27. Ramfjord, S. P.: Indices for prevalence and incidences of periodontal disease. J Periodontol 30: 51, 1959.

Send reprint requests to: Bill Becker, 810 N. Wilmot, B-2, Tucson, AZ 85711.

\section{In Memoriam}

\section{Sam E. Mills, D.D.S. 1899-1988}

Dr. Sam E. Mills, 88, died on January 28, 1988. He was born in 1899 in Bushy Creek, Texas. He attended the University of Texas where he earned a D.D.S. degree in 1923. After completing his training, he practiced general dentistry in Houston, Texas, until 1952.

He served with the U.S. Army in both World Wars and was honorably discharged as a Major in the Dental Corps during World War II.

He was a member of the American Academy of Periodontology since 1943, which made him eligible for the status of being a "grandfather" in the Academy. He had been president and vice president of his local dental society along with becoming a Fellow in the American College of Dentists. He was also a member of the American Dental Association, the Pierre Fauchard Academy, the Federation Dentaire Internationale, along with many other state, local and religious memberships.

\section{James P. Voigt, D.D.S.}

Dr. James P. Voight, of Clearwater, Florida, has recently died. He was born in 1937 in Sheboygan, Wisconsin. He attended Baylor University where he earned a B.A. degree in 1959 and a D.D.S. degree in 1963. He then continued his education and received an M.S. degree in periodontology in 1966 from the University of Alabama, where he was also an instructor.

In September of 1968, Dr. Voigt became an assistant professor in the Department of Periodontics at Temple University. In addition, Dr. Voigt contributed several articles on various aspects of periodontics.

He became a member of the American Academy of Periodontology in 1967. He was also a member of the American Dental Association, Royal Society of Health, Philadelphia Periodontal Society, as well as many other local societies. 